\title{
A gamified perspective in the learning of patrimonial architecture
}

\section{SIGRADI2018 TECHNOPOLITICAS \\ xxii congresso da sociedade iberoamericana de gráfica digital 22th conference of the iberoamerican society of digital graphics $07|08| 09 \mid$ novembro|2018 iau usp | são carlos | sp br}

\author{
Gilson Ferreira de Barros Filho \\ UFPB | Brazil | giil.fbf@gmail.com
}

Amélia de Farias Panet Barros

UFPB | Brazil | ameliapanetbarros@gmail.com

\begin{abstract}
The article reports the process of gamification applied to an educational context. This process had the goal to verify the potential of a virtual location, a loft in colonial style, in learning patrimonial architecture. Five stages were carried out: content research for the virtual location's design; development of the game in Unreal Engine 4.16; application of the game and similar pedagogical content with two groups of students; comparative analysis of the different learning experiences of both groups of students; application of the EGameFlow with students who interacted with the game. The results showed that the tool has great pedagogical potential.
\end{abstract}

Keywords: Gamification; Patrimonial architecture; Learning

\section{INTRODUÇÃO}

Os jogos digitais adquiriram um nível excepcional de realidade, mobilizando conhecimentos de diversas áreas e interagindo em prol de diferentes propósitos, para além do entretenimento. Essa interlocução dos elementos de design de jogos, em contextos que não são de jogos, tem sido denominada de gamificação e, vem atraindo pesquisadores em busca de estratégias que possam contribuir em contextos variados, como os educacionais, a exemplo desse trabalho.

$\mathrm{Na}$ área educacional a gamificação têm produzido algumas vantagens que colaboram com o aprendizado devido às interfaces atraentes, estimulando seus usuários ao enfrentamento dos desafios propostos pelos jogos. Para Freitas et al. (2016, p. 371) a "gamificação é, em si, uma metodologia de aprendizagem ativa em que os alunos podem se tornar aprendizes engajados e motivados nas atividades de aprendizagem."

Esse trabalho surge, justamente, motivado pelo desejo de contribuir no processo de aprendizado em arquitetura, utilizando para isso, as possibilidades das ferramentas interativas engajadas ao panorama digital. Nesse caso, com base nos princípios da gamificação foram utilizadas algumas técnicas referentes ao desenvolvimento de serious games ou jogos sérios, que surgem com o intuito de trabalhar conteúdo educacional e formativo. Os serious games, além de possibilitar o entretenimento, têm o objetivo de "[...] educar, formar, consciencializar, treinar e/ou desenvolver competências" (LOPES e OLIVEIRA, 2013, p. 12).

O serious game é uma espécie de método de ensino que tem o jogo como elo entre o que se quer ensinar e o indivíduo que está aprendendo. No contexto de criação de serious games, segundo Rocha (2017), é preciso ter clareza com relação ao objetivo do aprendizado e/ou do treinamento, precisamente, para garantir que 0 desenvolvimento, a evolução e a satisfação do usuário seja garantida. Por exemplo, o game (PING) "A Pobreza não é um Jogo" é um serious game que tem o objetivo de gerar discussão sobre temas como pobreza e exclusão social.

No processo de elaboração dos serious game deve existir planejamento pedagógico subsidiando o desenvolvimento, além da delimitação de características como roteiro, conceituação artística (game design), jogabilidade (gameplay) e definição da interface. (Morais, 2011, p. 23).

Os serious games trabalham com relações multidisciplinares e heurísticas para transmitirem algum conhecimento específico. Sua conceituação não foge do ambiente digital, uma vez que, existem princípios básicos a serem explorados que só o meio digital consegue atender.

Podemos perceber na ilustração abaixo que os serious games são utilizados em diferentes áreas com objetivos educacionais diversos ou visando o treinamento profissional.

Tabela 1: Público alvo dos serious games. Fonte: (MORAIS, 2011, p. 24)

PÚBLICO-ALVO DOS SÉRIOS GAMES

Profissionais da saúde

23,81

Militares

17,46

Pacientes sob tratamento

7,94

Ativistas 1,59 
Sobretudo, faz parte do processo de criação de um serious game, a etapa de avaliação, sem ela não há como verificar se os objetivos pedagógicos ou profissionais foram atingidos. (EMMERICH, 2016)

Mayer (2012) apresenta duas importantes razões para a existência da etapa de avaliação num processo de criação de serious games: a necessidade de prestar contas aos usuários sobre a eficácia do jogo, e; a responsabilidade que cabe aos seus desenvolvedores, no sentido de questionar os efeitos e consequências que, por ventura, os seus jogos possam estar causando aos seus usuários.

Nesse caminho, esse artigo relata um processo de gamificação aplicado em contexto educacional, por meio da criação e avaliação de um game. Tal processo teve o objetivo de verificar o potencial de um cenário de game no aprendizado da arquitetura patrimonial, tendo como objeto de estudo, um sobrado do período colonial brasileiro.

Não existem muitas referências que utilizam a relação arquitetura, patrimônio e serious games. Podemos citar o trabalho de Ghisolfi e Vizioli (2013), que trabalharam nessa interface, e criaram um quebra-cabeça digital, procurando valorizar e possibilitar a experiência por meio da reconstrução digital de patrimônio histórico.

O processo de aprendizagem da arquitetura patrimonial parte da premissa de valorização da herança de uma população, buscando atribuir novos conhecimentos a "criação cultural" da sociedade em questão.

Compartilhando de tal pensamento Ghisolfi e Vizioli (2013) atribuíram fundamental importância a construção de um discernimento voltado à realidade do patrimônio de uma comunidade. Ao negar essa necessidade de compartilhar informação, a própria sociedade inviabiliza a preservação dos bens culturais.

Nesse sentido, a reconstrução virtual, parece ser um caminho para o conhecimento e a valorização do nosso patrimônio arquitetônico.

\section{METODOLOGIA}

A pesquisa aqui relatada é de natureza exploratória e foi elaborada em cinco etapas metodológicas, cada uma delas com instrumentos e métodos específicos. As cinco etapas foram: pesquisa de conteúdo para a concepção do cenário do game; criação do game no Unreal Engine 4.16; aplicação do game e de conteúdo pedagógico semelhante em dois grupos de alunos; análise e mensuração comparativa do aprendizado aos dois grupos de alunos; e, aplicação do EGameFlow aos alunos que interagiram com o game. A seguir uma breve explicação de cada etapa.

$\mathrm{Na}$ primeira etapa houve a pesquisa de conteúdo conceitual e informativo, em torno das questões relacionadas à gamificação e serious games, além daquelas de cunho histórico que embasaram a concepção do cenário do game, no caso, o sobrado colonial. Tal pesquisa foi efetivada através da análise de referências bibliográficas para conhecimento e apreciação dos conceitos, dados, procedimentos metodológicos e a própria escolha do cenário mais apropriado para o game. Nesse momento, percebeu-se o grande potencial da arquitetura patrimonial como campo a ser investigado em situação de jogo, com propósitos educacionais claros e interdisciplinares, bem adequado ao perfil de usuário previamente definido, no caso, alunos iniciantes do Curso de Arquitetura e Urbanismo.

Uma pesquisa anteriormente realizada no $\mathrm{Pibic} / \mathrm{Cnpq}^{1}$ (FERREIRA, 2017), que perscrutava a história, forma e modo de morar no sobrado do período colonial brasileiro apresentou subsídios suficientes para que pudesse embasar o cenário do game. Assim, a partir da modelagem feita no Sketchup 16, outros elementos foram adicionados ao sobrado colonial para que o mesmo pudesse atingir o nível de detalhamento suficiente para um cenário de game, assim como, para os desafios pedagógicos que se apresentariam aos jogadores no percurso do jogo. Pormenores como a inserção do sobrado em contexto urbano de mesmo período, detalhes construtivos da própria edificação, assim como, mobiliários e utensílios que conferiram certo realismo ao cenário.

$\mathrm{Na}$ segunda etapa deu-se a concepção do game no Unreal Engine 4.16 tendo a modelagem como base. Anteriormente, algumas plataformas específicas para concepção de games foram pesquisadas e escolheu-se o Software Unreal Engine 4.16 por tratar-se de uma engine de games acessível, porém, com complexidade e variedade de elementos interativos suficientes para 0 propósito.

Para a escolha dessa ferramenta como máquina de criação do jogo efetuou-se, além de uma busca online, uma pesquisa de campo na BGS - Brasil Game Show, uma grande feira de games da América Latina. Nesse contexto, por meio de consultas à especialistas e diante do propósito e tempo disponível, a Unreal Engine 4.16 foi a alternativa mais viável, acompanhada da Unity 3D.

Assim, alguns questionamentos iniciais guiaram a trajetória de criação do game, foram eles: Como executar as ideias dentro da engine? Como aproximar os alunos do conteúdo pedagógico definido? De que forma o jogo irá transmitir tal conteúdo?

Com tais provocações, foram iniciados os estudos para a construção do storyboard, dos personagens, dos elementos coletáveis e de todos os desafios do game vinculados aos conhecimentos pedagógicos. Foi pensado como tais informações deveriam ser apresentadas, que tipo de suportes, como deveriam ser os audiovisuais, seus limites de tempo e quantidade de informação. Os vídeos informativos tiveram compilação e aplicação de sonoplastia feita no Windows Movie Maker. A modelagem 3D, feita inicialmente no Sketchup 16, com um aprimoramento da sua qualidade visual no Lumion 6, com pós-produção aplicada no Photoshop CC 2014. Para finalizar o processo foram feitos estudos de texturas, iluminação e humanização dos cenários com figuras humanas e paisagens importadas de obras do pintor francês Jean-Baptiste Debret a partir de sua viagem ao Brasil no século XIX.

\footnotetext{
${ }^{1}$ PIBIC: Programa Institucional de Bolsas de Iniciação Científica. CNPq: Conselho Nacional de Desenvolvimento Científico e Tecnológico
} 
Após a concepção do game houve, na terceira etapa, a sua aplicação, assim como, de conteúdo pedagógico semelhante, em forma de texto ilustrado, para dois grupos diferentes de onze alunos cada. Esse experimento teve o propósito de verificar o potencial do cenário de game criado no aprendizado da arquitetura patrimonial, objetivo principal desta investigação. (Ver Figura 1)

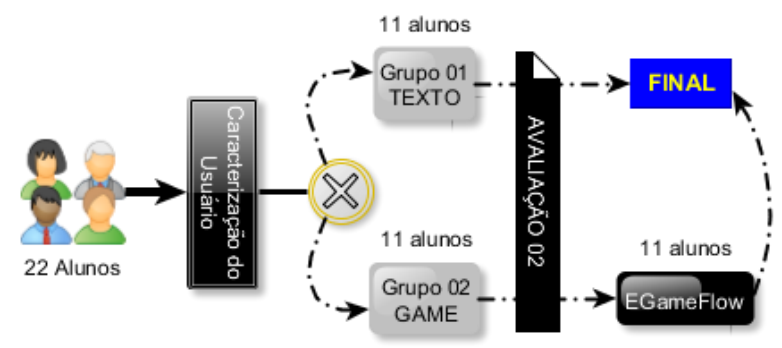

Figura 1: diagrama sobre o processo de verificação do aprendizado. Fonte: criação dos autores.

O perfil dos alunos foi escolhido de acordo com o nível de conhecimento em relação ao conteúdo pedagógico trabalhado no texto e no game. Assim, optou-se por alunos iniciantes do curso de Arquitetura e Urbanismo que ainda não havia trabalhado tal conteúdo nas disciplinas já cursadas. A turma de História da Arquitetura do Urbanismo II, localizada no segundo período do curso foi a escolhida.

A aplicação do teste piloto foi feita em quatro computadores, onde dois deles estavam com o grupo dos jogos e os outros dois com o grupo do texto. A média de tempo da aplicação dos alunos do grupo do texto foi menor, em torno de 15 minutos, em relação à média de tempo dos alunos do grupo do jogo, que foi de 22 minutos, devido ao tempo de familiarização dos alunos, com os comandos.

Ao final do experimento iniciou-se a quarta etapa, a análise e verificação comparativa do aprendizado construído pelos dois grupos de alunos. Para isso, aplicou-se aos alunos dos dois grupos, um questionário com perguntas referentes ao conteúdo pedagógico trabalhado. Dessa forma, foi possível a verificação do conhecimento apreendido pela experiência de maneira comparativa entre os alunos do grupo do jogo e aqueles do grupo do texto.

Por fim, na quinta etapa, foi aplicado um questionário complementar aos alunos do grupo do jogo, com a intenção de avaliar critérios referentes à jogabilidade e desempenho do game. Para isso, o EgameFlow foi a ferramenta escolhida para mensurar tal desempenho.

O EGameFlow é aplicado por meio de oito dimensões: 1_Concentração, 2_Desafios, 3_Autonomia, 4_Clareza dos Objetivos, 5_Feedback, 6_Imersão, 7_Interação Social e 8_Melhoria do Conhecimento. Cada dimensão apresenta vários itens para determinar seu desempenho. A satisfação do usuário é mensurada por meio de sete níveis, sendo o nível sete a maior satisfação. (TSUDA,
SANCHES, et al., 2014, p. 160). A seguir, serão apresentados os resultados.

\section{RESULTADOS}

Os resultados serão apresentados em três momentos que correspondem aos produtos da pesquisa: o cenário do game (o game propriamente dito); o resultado da aplicação do game e de texto com conteúdo pedagógico semelhante aos desafios do game; e, o resultado da EgameFlow.

\section{O CENÁRIO DO GAME THE HISTORY BOOK}

Nesse momento vamos abordar, sinteticamente, as cinco etapas utilizadas para o desenvolvimento do serious games, que intitulamos The History Book. No processo de criação do jogo, foi utilizado a sequência proposta pela Game Bible, tendo como referência Machado (2009) apud Morais (2011) que ajudou a organizar a ideia e todas as etapas do processo, pois trata-se de um material com algumas semelhanças, tanto no produto final quanto no processo de criação.

As etapas são: 1_Histórico do projeto; 2_Resumo do Projeto; 3 Jogabilidade e Mecânica; 4 Enredo, Universo e Personagem; 5_Projeto Técnico, conforme figura 02. Para esse artigo, o percurso será resumido por meio dos elementos estruturadores da concepção do jogo.

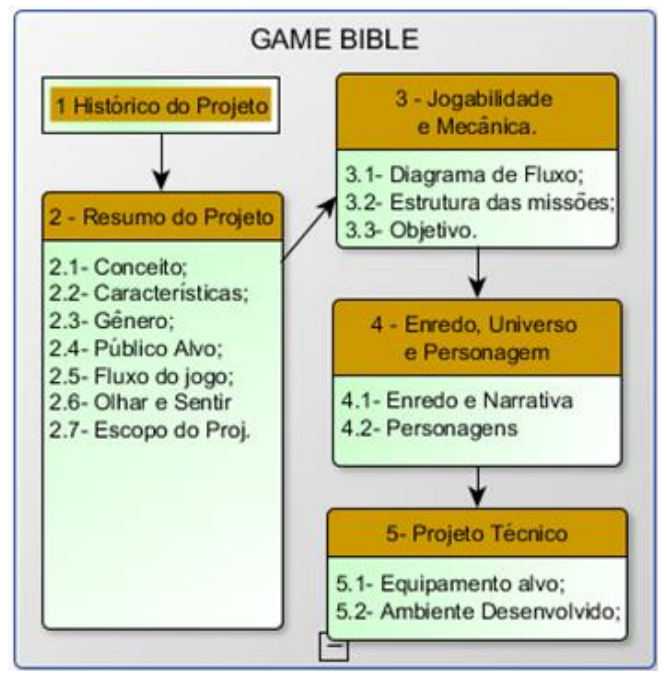

3

Figura 2: etapas da Game Bible Fonte: Machado (2009) apud Morais (2011) adaptado pelos autores.

Inicialmente foi preciso definir as metas e objetivos a serem atingidos pelo jogo no processo de construção de conhecimento realizado aluno, a partir da sua interação com o cenário do game. Essa fase teve o intuito de compreender que tipo de conhecimento poderia ser investigado nesse cenário criado. Nesse sentido, a construção do cenário não se limitou ao uso da engine por se tratar do desenvolvimento de um serious games com objetivos pedagógicos. Assim, foi necessário a utilização de recursos multimídia como fotografias, retrabalhos em quadros antigos, criação e edição de vídeos, modelagem $3 \mathrm{D}$, efeitos sonoros, narração, dentre outros. 
Como exemplo, no caso das paisagens e dos mobiliários presentes no cenário, foi feita uma análise em fotos e pinturas da época e encontramos nas pinturas de JeanBaptiste Debret uma fonte importante de dados. Outros aspectos ou imagens foram pesquisados em informações presentes em sites específicos do assunto.

Para reforçar a interação e imersão do aluno foram criados personagens que servem de elo entre a realidade e a história que o cenário representa. Com esse propósito, foram concebidos quatro personagens que norteiam todos os acontecimentos e dão sentido ao processo de gameplay e as respectivas decisões dos alunos dentro do jogo: Navi (o mago); Berth (a xícara de porcelana); Mell e Lian (adolescentes). A seguir podemos observar o resumo do fluxo do jogo (história do game).

\section{RESUMO DO FLUXO}

Uma pequena narrativa foi criada antes do início do jogo para que o aluno pudesse se envolver com o cenário proposto. Nela localizamos o usuário no tempo e no espaço, apresentando, ao mesmo tempo, os personagens. Segue a introdução apresentada no início do jogo:

Em um mundo não tão distante, onde a magia se encontra à espreita, temos a possibilidade de viajar no tempo e no espaço para conhecer novas realidades arquitetônicas. Graças ao mago e arquiteto conhecido por Navi foi criado o History Book, cujo poder só será ativado com a ajuda da xícara falante Berth, sua assistente. O café mágico preparado em Berth, a xícara de porcelana, tem o poder de ativar os portais mágicos do livro/tempo, levando quem tomá-lo às tipologias arquitetônicas mais remotas, localizadas em períodos variados da história. Com a missão de encontrar informacõos sobre as tipologias, os avatares Mell e Lian entram nos portais para conhecer o máximo de conhecimento arquitetônico que conseguir, auxiliando Navi a reconstruir seu catálogo mágico, onde reúne conteúdos sobre todas as edificações do mundo humano (Barros Filho, 2018, p. 45).

Com essa narrativa o aluno é inserido em um cenário de RPG, com liberdade para construir seu próprio caminho de aprendizado. Assim, para iniciar a aventura o jogador é transportado para a paisagem de uma rua colonial com tipologias da época, tendo em destaque, o sobrado que será percorrido pelo aluno. (Figura 3)

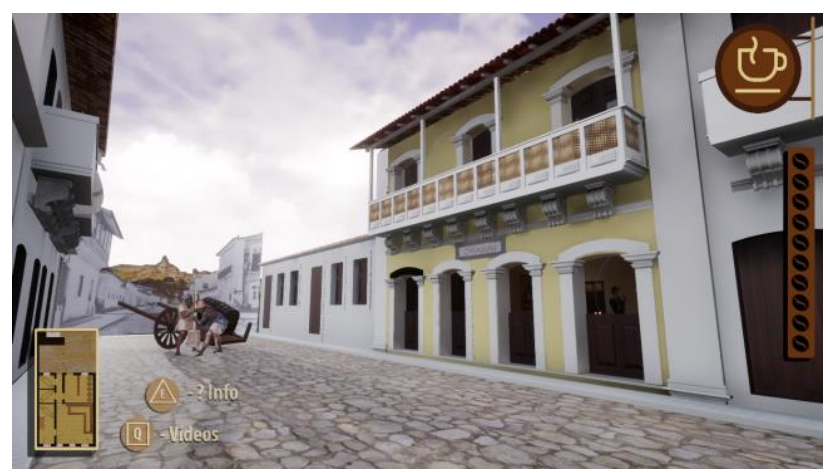

Figura 3: cena inicial do jogo. Fonte: Criação dos autores.

Ao longo do percurso pelo sobrado, são apresentados elementos áudio visuais para melhor interação no cenário gerando um estímulo de aprendizado multissensorial. Esses elementos são apresentados de duas formas: a partir de informativos em forma de papiros, distribuídos em 14 lugares, constituídos de imagens com textos autoexplicativos, e por meio de 5 quadros interativos, constituídos de imagens e animações narradas pela voz da Berth, que explica de maneiras direta as informações apresentadas no vídeo.

Para gerar os desafios e incentivar o usuário a percorrer todo o cenário, foram espalhados 10 coletáveis em forma de grãos de café. $O$ processo de coleta desses elementos foi programado para acontecer quando o aluno se aproxima do item, provocando a curiosidade para percorrer todo o cenário, e assim, absorver o máximo de conhecimento.

Esses elementos estão diretamente relacionados aos níveis e obstáculos do sobrado, onde o aluno só consegue ter acesso ao próximo pavimento/nível quando coletar 5 dos 10 grãos de café. A figura 4 demonstra o diagrama de desenvolvimento dos níveis e obstáculos dispostos ao longo do jogo

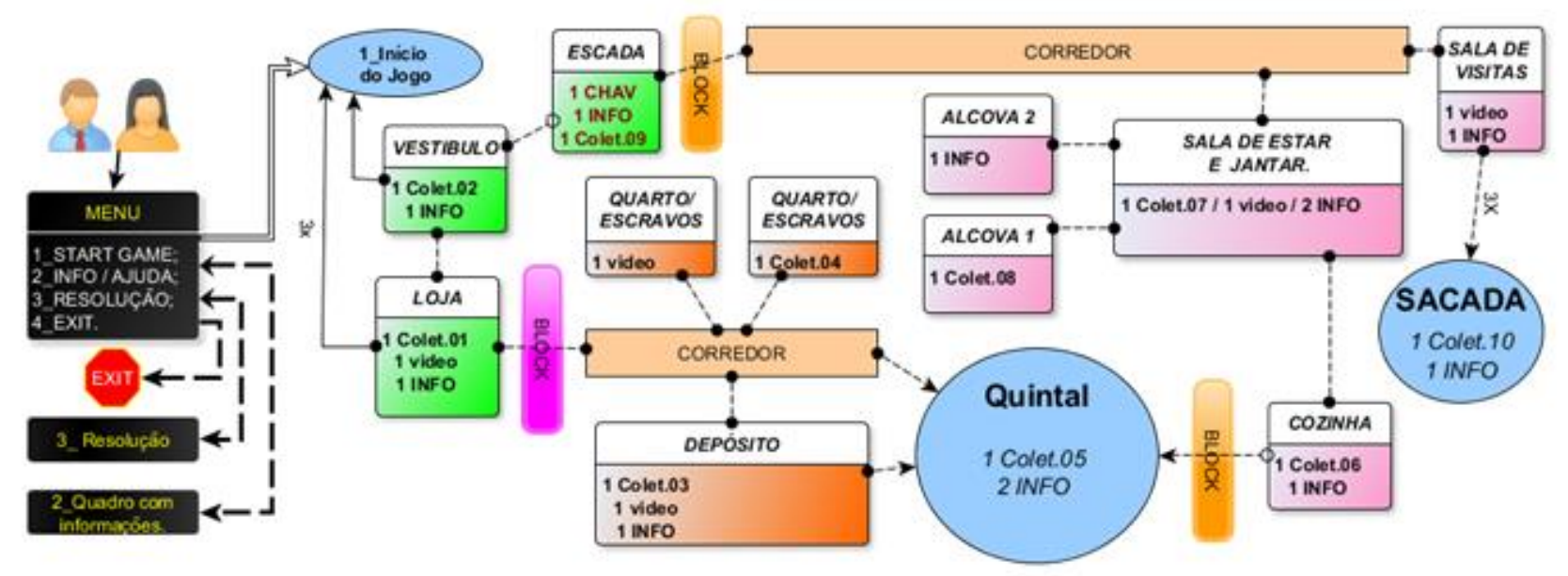

Figura 4: Diagrama do desenvolvimento dos níveis de Fluxo do jogo. Fonte: Acervo dos autores 
A figura 5, apresenta todos os ambientes do sobrado devidamente nomeados e com os seus respectivos elementos interativos. Esses ambientes foram divididos por cor e forma. Os ambientes circulares e de cor azul representam as áreas externas do sobrado, aqueles de cor verde representam os ambientes que dão acesso ao cenário e, os de cor laranja, são aqueles que possuem nível de dificuldade intermediário. Por fim, os ambientes de cor rosa compõem a etapa final, no nível superior do sobrado.

No decorrer de todo o processo o usuário tem contato direto com a interface fixa do game, assim como, com a composição dos ambientes. De acordo com a imagem a seguir, podemos perceber oito dos elementos responsáveis por criar a interatividade geral e os elementos de aprendizado, assim como, a localização espacial e o auxílio necessário ao jogador para o seu desenvolvimento dentro do cenário gamificado.

Para melhor entendimento desses elementos foram organizados três grupos principais de acordo com suas funções de localização espacial, aprendizado e auxílio à jogabilidade.

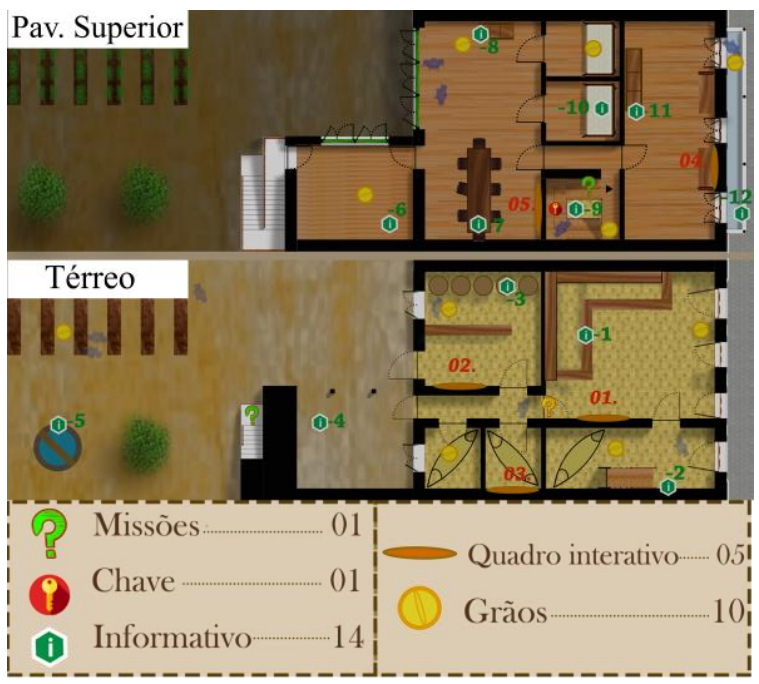

Figura 5: Mapa de interatividade. Fonte: Criação dos Autores

Assim, os números marcados na figura 7 possuem as seguintes funções: I - Localização, composto por: 1. Planta /Mini-mapa; 7. Localizadores, cuja função é auxiliar o usuário a entender sua localização espacial dentro do sobrado, assim como, aprender o nome dos ambientes em que se encontram; II - Aprendizado composto por: 2. Vídeos informativos; 3. Mobiliários Locais; 6. Papiros, responsáveis por transmitir informação sobre a arquitetura e modo de viver daquela época. III - Auxílio à jogabilidade, composto por: 5. Informativos; 4. Botões de Ação; 8. Coletáveis, elementos que servem de guia e auxílio para o desenvolvimento e feedback do aluno perante o cenário gamificado. No fim do jogo os alunos do grupo do game devem ter acessado todos os ambientes e, consequentemente, acessado todo o conteúdo pedagógico apresentado para que possam ser avaliados sobre as informações arquitetônicas coletadas.

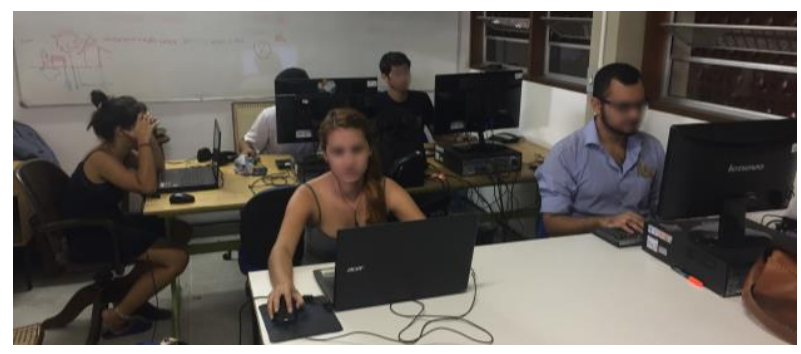

Figura 6: Aplicação do Game. Fonte: Autores.

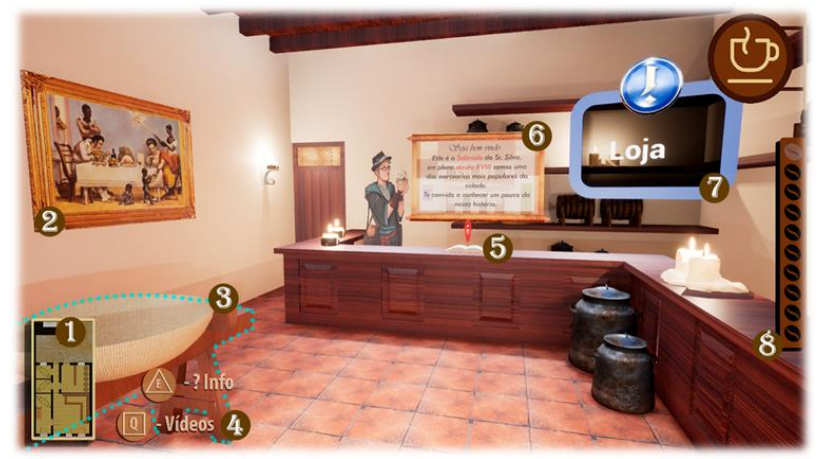

Figura 7: Interface de interação. Fonte: Criação dos Autores.

\section{OS RESULTADOS DA APLICAÇÃO DO GAME (GRUPO 01) E TEXTO (GRUPO 02)}

Após a aplicação das experiências nos dois grupos, o grupo que vivenciou o game (11 alunos) e o grupo que trabalhou com o texto informativo (11 alunos), foi aplicado um questionário relativo ao conhecimento trabalhado nos dois instrumentos de aprendizado, como apresentado na quarta etapa da metodologia.

Tal questionário teve o objetivo de mensurar 0 conhecimento construído pelos alunos ao longo das experiências para verificar, de forma comparativa, a eficiência do jogo como ferramenta pedagógica em relação à forma tradicional de construção do conhecimento, no caso desse experimento, o texto ilustrado.

As perguntas elaboradas no questionário foram apresentadas como uma espécie de dúvida, narradas pelo Navi, como Mago e atribuidor da missão. As mesmas questões foram apresentadas ao grupo do texto, que por sua vez, receberam as mesmas informações presentes dentro do cenário gamificado, através de um texto ilustrado. Como exemplo, seguem algumas das questões aplicadas:

Questão 01_Cada período histórico produziu a arquitetura de diversas maneiras, procurando relacionar sua forma à estrutura urbana. O traçado do período colonial fragmentou o tecido urbano em quarteirões formados por lotes estreitos e compridos, onde, na sua porção central, concentravam-se os quintais formados pelos fundos de cada lote. Como se dava a implantação das residências nesses lotes estreitos? (Barros Filho, 2018, p. 88)

Questão 02_ De acordo com Reis Filho (1987), as residências seguiam um padrão fixado pela Carta Régia, que definia as dimensões e número de aberturas, altura dos 
pavimentos e o alinhamento com a rua. A organização espacial do seu interior também seguia um padrão. No caso do sobrado de uso misto, como se dava sua distribuição funcional? (Barros Filho, 2018, p. 88)

Questão 03 Devido aos lotes estreitos e compridos, as residências seguiam uma implantação que resultava em uma volumetria bastante rígida, definida apenas pelas fachadas frontal e de fundos. Nessa configuração, como se dava a solução do telhado? (Barros Filho, 2018, p. 89)

Questão 05_Com os lotes estreitos, sua ocupação sem recuos e o clima quente e úmido, quais as soluções utilizadas na construção das residências para amenizar a sensação térmica? (Barros Filho, 2018, p. 90)

As questões foram de múltipla escolha com quatro alternativas e apenas uma resposta correta. Após a análise das respostas dos alunos sobre cada questão e, consequentemente, um apanhado geral sobre o aproveitamento de cada grupo, esses foram os resultados:

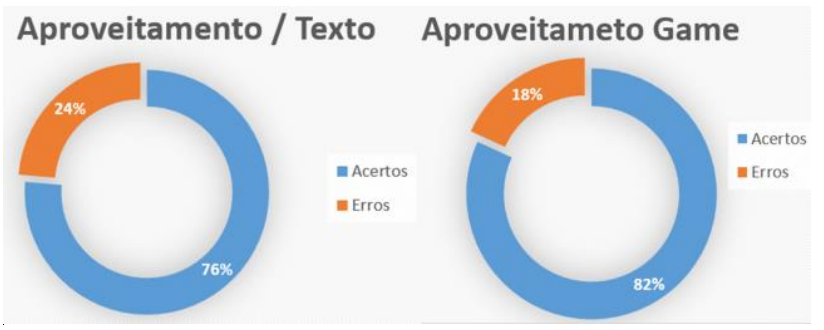

Figura 8: Aproveitamento dos testes. Fonte: Criação dos autores.

Pode-se observar que o cenário gamificado teve um aproveitamento superior ao método tradicional, no caso, um texto ilustrado. Com uma diferença de 6 pontos percentuais entre os resultados obtidos, o grupo que usou - game para construir seu conhecimento sobre a arquitetura e o modo de vida no sobrado colonial se destacou com um aproveitamento de $82 \%$ das questões em relação ao grupo do texto, que teve um aproveitamento de $76 \%$ com o mesmo questionário aplicado.

A partir dos dados demonstrados acima, pôde-se verificar o potencial do cenário de game criado para o aprendizado do objeto histórico arquitetônico, objetivo principal deste experimento. Ademais, a forma lúdica e multissensorial da ferramenta criada permitiu um aprendizado prazeroso e interativo.

\section{OS RESULTADOS DA APLICAÇÃO DO EGAMEFLOW}

Como apresentado na quinta etapa da metodologia, foi aplicado um questionário seguindo o método de análise de jogos educacionais conhecido como EGameFlow, que visa mensurar a satisfação do usuário através de uma escala de 0 a 7 perante 0 cenário gamificado apresentado. Os resultados obtidos apresentam os pontos fracos e as potencialidades da eficácia do jogo como ferramenta de construção do conhecimento, a partir do ponto de vista do jogador.

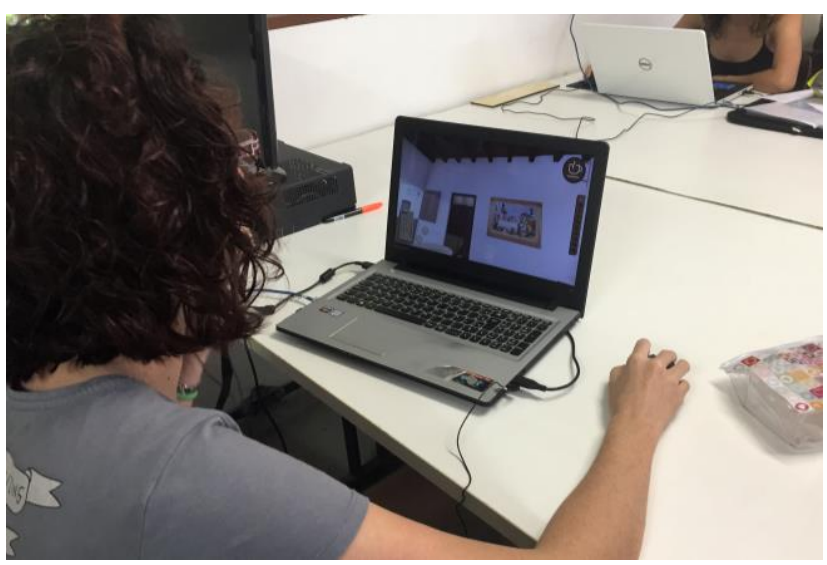

Figura 9: Aluna vivenciando o game Fonte: Autores.

\section{EGameFlow}

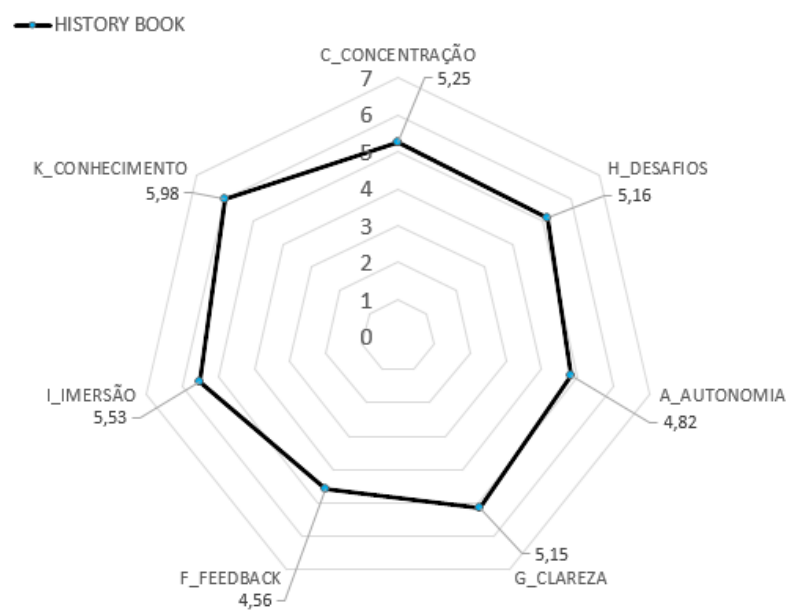

Figura 10: Gráfico de notas do EGameFlow. Fonte: Criação dos autores.

De acordo com a figura 10 a nota geral que o jogo obteve foi de 5,2 caracterizando um aproveitamento médio/alto considerado aceitável. Levando em consideração que a nota mais alta é a 7, o tópico conhecimento aproximou-se, consideravelmente, obtendo 5,98 pontos em sua avaliação, acompanhado da imersão $(5,53)$ e do feedback $(4,56)$.

\section{DISCUSSÃO (CONSIDERAÇÕES FINAIS)}

A experiência possibilitou a aplicação de técnicas de gamificação no contexto de um serious game para verificar o potencial de um cenário de games no ensino da arquitetura histórica patrimonial.

No contexto da área de conhecimento e, principalmente, no contexto do Curso de Arquitetura e Urbanismo ao qual os autores fazem parte, essa experiência apresentou um impacto bastante positivo em vários aspectos. Seu desenvolvimento teve o grande desafio, com fins pedagógicos, de trabalhar no limiar de duas áreas de conhecimento, a arquitetura, pelo objeto trabalhado, e a área relacionada à engenharia dos jogos digitais.

Nessa experiência, a escolha do cenário do game, um sobrado colonial, contribuiu para a compreensão da 
espacialidade e do suposto uso, baseado em pesquisas, de algo que não mais existe, mas que pôde ser vivenciado digitalmente.

Com a engine trabalhada foi possível concretizar as características importantes do objeto arquitetônico, para que os conhecimentos inerentes à tipologia pudessem ser trabalhados como: espacialidade e ambiência, organização e uso, detalhes construtivos, modo de vida, mobiliários, história, entre outros.

O objetivo principal da experiência em verificar o potencial do cenário de game criado no aprendizado da arquitetura patrimonial foi comprovado, de forma comparativa, por meio da aplicação de questionários que puderam mensurar, minimamente, o grau de conhecimento adquirido pelos alunos.

Os resultados demonstraram que os alunos que interagiram com o game conseguiram assimilar o conhecimento proposto pela ferramenta, obtendo um aproveitamento superior àqueles alunos que trabalharam os mesmos conhecimentos por meio do texto ilustrado.

No entanto, algumas ponderações são necessárias. Destacamos o reduzido número de alunos nos dois grupos, por ser uma experiência científica de pequeno porte, o que nos impossibilita tecer resultados mais significativos em termos quantitativos. Apenas 11 alunos em cada ferramenta não sinaliza um resultado definitivo quanto à eficiência do serious game criado. Apesar disso, em termos qualitativos, percebemos aspectos que tornam o aprendizado mais agradável pela sua possibilidade de interação, vivência espacial, ludicidade, inovação e afinidade com os mecanismos de jogos de lazer, contribuindo no aprendizado de maneira prazerosa.

Com a aplicação do EGameFlow à equipe que interagiu com o cenário de game foi possível avaliar o alcance, potencialidades e limites da ferramenta a partir da avaliação e das observações complementares feitas pelos alunos. Esse fato foi além das expectativas e essencial para o aperfeiçoamento do game.

Vale destacar que todas as considerações dos alunos sobre o experimento foram devidamente analisadas e serviram para percebermos as lacunas e confirmar alguns aspectos, como por exemplo, o potencial da ferramenta na colaboração da interação e acessibilidade das pessoas com alguma deficiência. Citamos o caso de um dos alunos que ficou no grupo do game e apresentava uma deficiência visual. Mesmo com restrições de 80 \% de sua visão, o aluno teve um ótimo desempenho, resguardando sua autonomia com independência.

No trato das limitações e considerações importantes obtidas com o teste aplicado, destacamos a necessidade de melhoria com relação aos requisitos mínimos para o funcionamento do game, como exemplo, citamos a necessidade de ter bons computadores para a sua aplicação, do contrário, o game não apresenta velocidade e bom desempenho.

Ainda que, em pequena proporção, destacamos a dificuldade de alguns alunos em interagir com o cenário apresentado, por falta de afinidade com os comandos de mobilidade do game. Esse aspecto nos motiva à encaminhamentos, cujos avanços tecnológicos possam contornar essa limitação de maneira mais adequada.

Entendendo o vasto potencial do tema apresentado, cabe às pesquisas futuras dar continuidade aos vários aspectos abordados nessa trajetória, entre eles, a forma de visualização do cenário que a engine proporciona. Nesse caso, a possibilidade de uma nova aplicação em outras plataformas de jogos como smartphones e tablets e/ou uma futura utilização do óculos VR (Realidade Virtual), elevando o nível de interação e imersão do aluno. O próprio jogo também abre possibilidades para a inserção de outras fases e de outras tipologias arquitetônicas.

Neste sentido, a aplicação da gamificação no aprendizado da arquitetura patrimonial serviu para demonstrar o potencial de métodos de ensino mais interativos, motivando alunos e professores às experiências mais lúdicas, incorporando as ferramentas digitais que estão disponíveis e que fazem parte do universo dos nativos digitais.

Esse trabalho foi, portanto, uma pequena amostra diante de um universo de possibilidades que cresce a cada dia. Sabemos que nem todas as universidades dispõem de recursos tecnológicos adequados para o desenvolvimento de tais ferramentas, ao mesmo tempo em que, para serem aplicadas em sala de aula, necessitam de uma capacitação por parte do corpo docente.

O processo de trabalho e seus resultados procuraram, portanto, atender ao desejo inicial de contribuir com outras formas de construção do conhecimento, a gamificação foi apenas um dos caminhos que existem para aliar conhecimento e entretenimento.

\section{REFERÊNCIAS}

Barros Filho, G. F. (2018). Jogos de conhecimento uma arquitetura gamificada. UFPB, Departamento de Arquitetura e Urbanismo. João Pessoa: UFPB. Acesso em 2018

Barros Filho, Gilson Ferreira;. (2017). Arquitetura residencial em João Pessoa: história, forma e modo de morar (re)apropriados através de recursos digitais. PIBIC, Departamento de Arquitetura e Urbanismo. João Pessoa: UFPB.

Emmerich, K.; Bockholt, M. Serious Games Evaluation: Processes, Models, and Concepts. In: Entertainment Computing and Serious Games. Springer International Publishing, 2016.

Freitas, S. A., Lima, T., Canedo, E. D., \& Costa, R. L. (2016) Gamificação e avaliação do engajamento dos estudantes em uma disciplina técnica de curso de graduação. XXVII Simpósio Brasileiro de Informática na Educação, pp. 370-379.

Ghisolfi, E. M.; Vizioli, S. T. (2013) A arquitetura patrimonial através dos jogos digitais. Graphica'13, Florianópolis, 3,4,5 Novembro 2013. n. p.

Lopes, N., \& Oliveira, I. (junho de 2013). Videojogos, Serious Games e Simuladores na Educação: usar, criar e modificar. EFT - Educação, Formação e Tecnologia. Acesso em 28 de Maio de 2018, disponível em http://eft.educom.pt

Mayer, I. (2012). Towards a comprehensive methodology for the research and evaluation of serious games. Procedia Comput. Sci. 15. 
Morais, A. M. (2011). Planejamento e desenvolvimento de um serious game voltado ao ensino de saúde bucal em bebês. UFPB - Dissertação de Mestrado., João Pessoa.

Tsuda, M., Sanches, V. M., Ferreira, T. G., Otsuka, J. L., \& Beder, D. M. (12 de Novembro de 2014). Análise de métodos de avaliação de jogos educacionais. SBC - Proceedings of SBGames 2014, pp. 158-166. 